\title{
THE INTEGRATED 3D SURVEY FOR UNDERGROUND ARCHAEOLOGICAL ENVIRONMENT
}

\author{
D. Ebolese ${ }^{1} *$ M. Lo Brutto ${ }^{2}$, G. Dardanelli ${ }^{2}$ \\ ${ }^{1}$ Department Cultures and Societies, University of Palermo, Italy, donatella.ebolese@unipa.it \\ ${ }^{2}$ Department of Engineering, University of Palermo, Italy, (mauro.lobrutto, gino.dardanelli)@unipa.it
}

\section{Commission II}

KEY WORDS: 3D survey, Archaeology, Laser scanning, Close-range photogrammetry, UAV, 3D Modelling

\begin{abstract}
:
The task of documentation and conservation of Cultural Heritage defines the challenges that geomatics techniques have to overtake in order to provide different solutions that combine the automation of processes with accurate results. The employment of integrated technologies allows improving the documentation of Cultural Heritage from a quantitative and qualitative point of view. The use of range and image-based techniques ensures the possibility to completely record articulated structures such as building with underground environments. The latter present often problematic survey conditions that imposed well planned and appropriate solutions. In this context, the paper presents the results of a 3D survey of the underground "Sybil hypogeum" and the related overhead church located in the Archaeological Park of Lilibeo (Marsala, Southern Italy). An integrated survey was planned in order to combine laser scanning technology with terrestrial-based and Unmanned Aerial Vehicle (UAV)-based photogrammetry to acquire the three-dimensional data of the whole complex (underground environments and overhead church). The aims of the work are related to test a topographic approach by a traverse method for scans registration and to archive a complete and detailed 3D model of the whole area. This model could be used to prevent the risk of information's loss and to improve the knowledge of the site.
\end{abstract}

\section{INTRODUCTION}

Accurate and complete documentation of archaeological underground environments, especially if they are decorated, is a challenging task in order to promote the enjoyment of tourists (often these sites are inaccessible), to favour the conservation of the sites and to prevent the risk of information's loss. In particular, the preservation of underground archaeological environments is a demanding task because of the natural degradation that could damage archaeological finds or remains. In this context, modern geomatics techniques can be a valuable aid for survey and 3D documentation of these environments. Detailed documentation through geomatics approach shows many potentialities for non-contact mapping and recording of 3D data (Remondino et al., 2011) and for promoting the digital preservation (Basantes et al., 2017).

$3 \mathrm{D}$ data can favour the high-resolution preservation of the $3 \mathrm{D}$ information improving the analysis on complex surfaces and adding value to the archaeological documentation (Lindgren and Galeazzi, 2013). Geomatics technologies can allow to preserve the memory of the monument, to monitor their state of conservation over time and to support technical intervention for conservation (Saulli et al., 2018). The employment of integrated geomatics technologies allows also improving the documentation quality of underground environments and painting decorations, both for the study of the geometric structure and for the description of details or decorations (Torres-Martínez et al., 2017). Moreover, 3D data can be used also for the virtualization of archaeological underground environments, to produce virtual visits and apply virtual restoration techniques (Beraldin et al., 2002).

$3 \mathrm{D}$ data can be captured by a terrestrial laser scanner or closerange photogrammetry. The use of terrestrial laser scanner for heritage preservation and research is becoming a common strategy to acquire millions of points at a very high spatial resolution on complex surfaces. As compared to the conventional method, these technologies provide a non-contact solution and fast and accurate data capture method (Majid et al., 2017). The terrestrial laser scanning is the fastest and more reliable approach to directly acquire $3 \mathrm{D}$ data and to monitor them over time (Lo Brutto et al., 2018); it allows a significant development of multidisciplinary non-destructive diagnostic investigations (Fais et al., 2018).

Photogrammetric data produces highly detailed photographic textures that can maximize the accuracy of scanned 3D data to correctly convey diagnostic coloration information (Dostal and Yamafune, 2018).

The integration of terrestrial laser scanner and close-range photogrammetry can assist in the generation of spatial and visual records of heritage sites (Davis et al., 2017).

The 3D survey and documentation of underground archaeological environments present some difficulties, due to the complex geometry of the structures, generally characterized by irregular shapes, the narrow spaces and the difficult to access with 3D survey devices (Chías et al., 2017). Moreover, some problematic conditions as the high level of humidity, the low temperature and the insufficient environment lighting should be considered for the survey (Gallay et al., 2015).

Another important issue in underground surveying is related to the orientation and registration of underground surveys to the surface ones; this aspect requires a careful planning phase and the use of suitable devices and appropriate working approaches. The paper presents an integrated 3D survey of the "Sybil hypogeum" inside the Archaeological Park of Lilibeo (Marsala, Southern Italy). The hypogeum is composed of three rooms and it is located under a church where the entrance to the

\footnotetext{
* Corresponding author
} 
underground environments is arranged. The work is aimed to generate a complete and accurate $3 \mathrm{D}$ model of the inner cave rooms and of the overlying church.

A terrestrial laser scanner survey was planned to perform scans on both the interior of the cave and the interior and the exterior of the church. The laser scanner survey was also suitable to test a topographic approach by a traverse method for scans registration. This approach is very useful for the study of underground environments where the structure complexity could make cloud-to-cloud registration very difficult.

A close-range photogrammetric survey all around the inner rooms of the hypogeum was also carried out in order to document wall paintings and mosaic decorations onsite. Furthermore, the need to acquire the entire external surface of the church required the integrated use of terrestrial laser scanners and UAVs (Unmanned Aerial Vehicles) to complete the 3D documentation. The integration of terrestrial laser scanner survey with terrestrial-based and UAV-based photogrammetry improves the advantages for the mapping and recording aims (Lo Brutto et al., 2017).

Terrestrial laser scanner survey of the hypogeum and of the outer wall of the church were also used to evaluate the terrestrial-based and UAV-based photogrammetry acquisitions of the same structures.

\section{THE "SYBIL HYPOGEUM"}

The Archeological Park of Lilibeo extends for about 28 hectares and is inside the city of Marsala (Figure 1). The Park preserves a considerable area of Lilybaeum, the ancient city of Marsala, founded in the IV century B.C. by the Punic.

Currently, the ruins of the Decumanus Maximus and several luxurious private buildings, with a wealth of thermal baths and polychrome mosaics, show the Lilibeo prosperity until the Roman Empire.

The "Sybil hypogeum" is one of the most suggestive archaeological remains of the Archeological Park of Lilibeo; it is located in south-west area of the Park (Figure 2). The hypogeum is completely excavated in the rock to a depth of about 4.8 meters from the surface. The entry presents a treacherous staircase and a short passage tunnel (Figure 3).

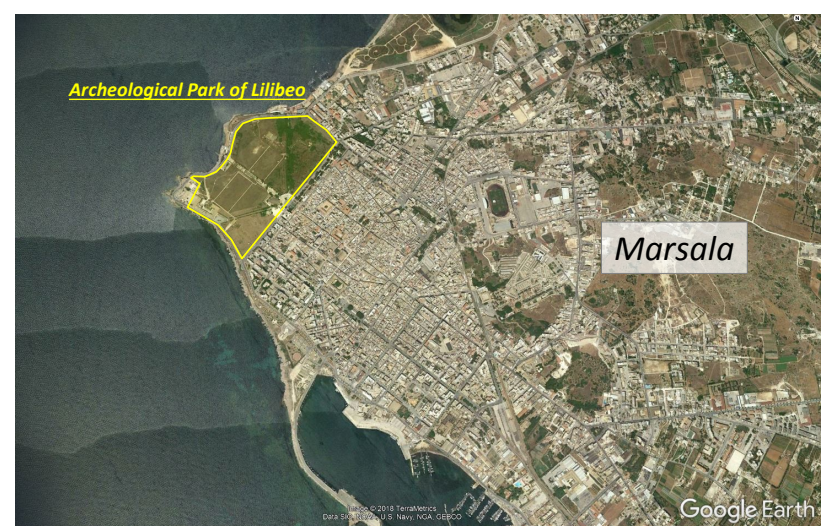

Figure 1. Archeological Park of Lilibeo (from Google Earth $\odot$ ).

The structure is characterized by a main circular space and two other connecting rooms on the northern and the western sides. All the rooms had wall paintings and mosaic floors; many of which are now lost or in a bad state of conservation. The central room was decorated in the Roman-Imperial period with wall paintings and paved with a mosaic depicting fish, of the late IIearly III century AD.
In the northern apsidal-shaped room, the mosaic floor showed traces of the original white background decoration with cruciform flowers of the late fourth-early fifth century AD.

The western room too was entirely covered by wall paintings, some of which are still visible (Figure 4). There are panels and mirrors of fake marble in the lower register and panels with symbolic motifs on the central wall and on the apse on the right in the upper register, bordered by a ribbon band with stylized flowers. These decorative motifs are widely compared in funerary paintings and early Christian mosaic cycles of the fourth century (Lima, 1997).

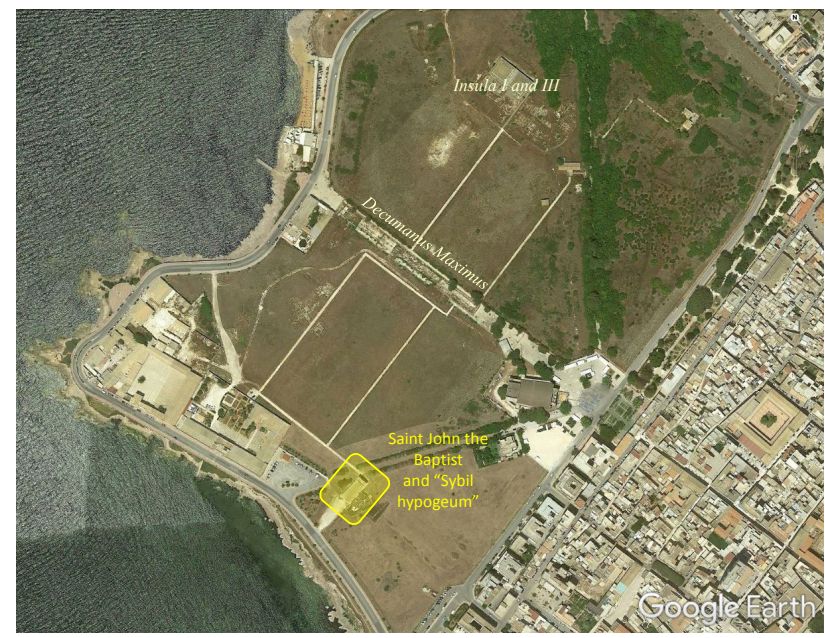

Figure 2. Localization of the "Sybil hypogeum" inside the Park (from Google Earth $($ ).

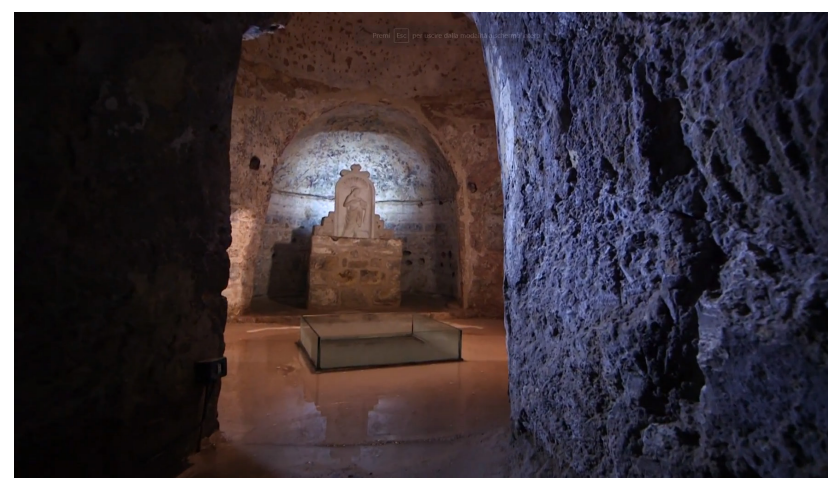

Figure 3. The entrance of the "Sybil hypogeum".

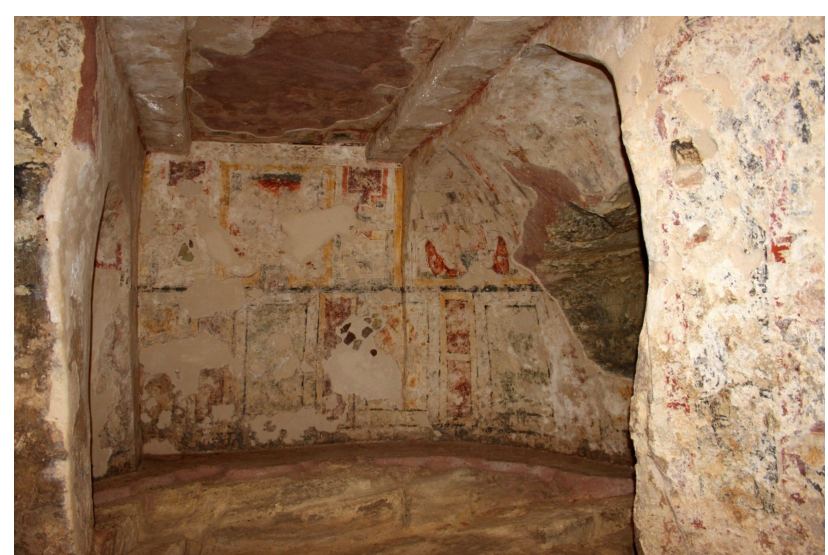

Figure 4. Wall paintings decoration. 
In the XVI century, a stone altar with a high relief of probable Gaginesque school, depicting John the Baptist holding in his arms the Agnus Dei, was built. Just behind the altar, from a small cavity at floor level, flows the spring that feeds the central basin by means of a channel.

The presence of the rich water table, emerging from the square well at the center of the central environment, emerging from capillary rise and influence of the tides, has caused the deterioration of the mosaics and the loss of much of the decoration.

Entry to the hypogeum was allowed by two openings in the floor of the nave of the church, on the east and the south sides. Today, access to the cave is only possible via the path to the south (Figure 5), while the entrance to the east has been preserved only for the ancient ramp on the ceiling of which is inserted a relief slab with Latin cross of the fifth-sixth century.

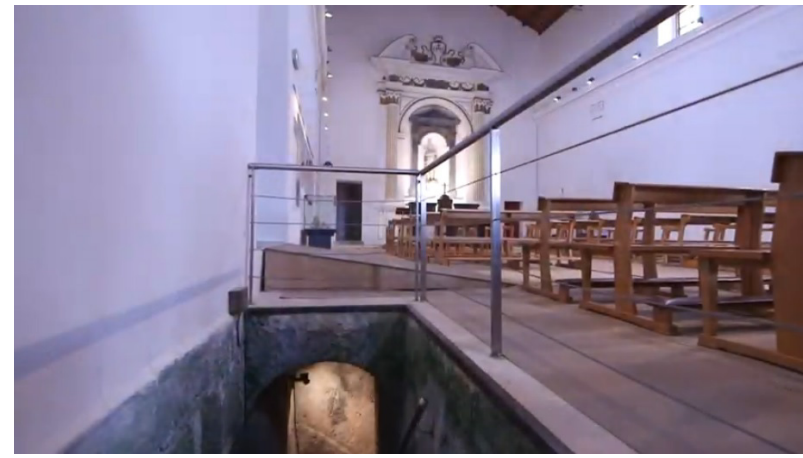

Figure 5. Southern entrance in the Saint John Church.

The first mention of the overhead church, built on ancient Roman structures, is dated to the end of the XII. At present, the church shows a single longitudinal nave of about $20 \mathrm{~m}$ in length and it is characterized by an altar decorated with a statue of Saint John the Baptist attributed to Antonello Gagini.

The presence of spring water inside "Sybil hypogeum" was related, over the centuries, to the cult of the Sybil and of Saint John the Baptist; for this reason, the church was dedicated to Saint John the Baptist since the XII century (Cusenza and Vecchio, 2008).

\section{DATA ACQUISITION}

In order to achieve a complete and detailed survey of the "Sybil hypogeum" and of the overlying church, an integrated terrestrial laser scanner - photogrammetry survey was carried out. Even if the survey campaign was organized on different days, all the steps have been carefully planning, in order to provide datasets that can be integrated into the post-processing phase.

\subsection{Laser scanner acquisition}

Terrestrial laser scanner survey was planned to generate a complete point cloud from the inner of the hypogeum to the exterior of the church.

The survey was carried out using a Topcon GLS-2000M, a fulldome time-of-flight laser scanner. The instrument, with a distance measuring range up to 350 meters and a scan rate up to $120.000 \mathrm{pts} / \mathrm{sec}$, provides a $360^{\circ}(\mathrm{H}) \times 270^{\circ}(\mathrm{V})$ Field of View. This device is equipped with dual (5 MP) cameras: a $170^{\circ}$ wideangle and $8.9^{\circ}$ tele-photo camera; furthermore it can recognize the "first pulse" and "last pulse" and offers first/last pulse selection to be taken as measuring result (TOPCON, 2018). But one of the most interesting features of this device is the possibility to use it as a total station. In fact, the data acquired by GLS-2000M can be registered using various registration methods; a classical cloud-to-cloud registration process, a target scanning mode (using also topographic prims) and a topographic approach by a traverse method. This last method could be very useful for long-distance measurement or for sites with complicated object shape. With the traverse method, the scanner work exactly as a total station measuring the back- and foresight scan positions using a prism. This allows to automatically align all scans along a traverse.

For the laser scanner acquisitions, a traverse, that starts from the interior of the hypogeum, goes inside the church and ends around the outside of the church was planned.

The traverse has been carried out by 16 scan points: 4 scan points were planned to entirely document the hypogeum rooms; 4 for the passage tunnel and the staircase; 2 scan points for the interior of the church and 6 around the external walls of the church (Figure 6).
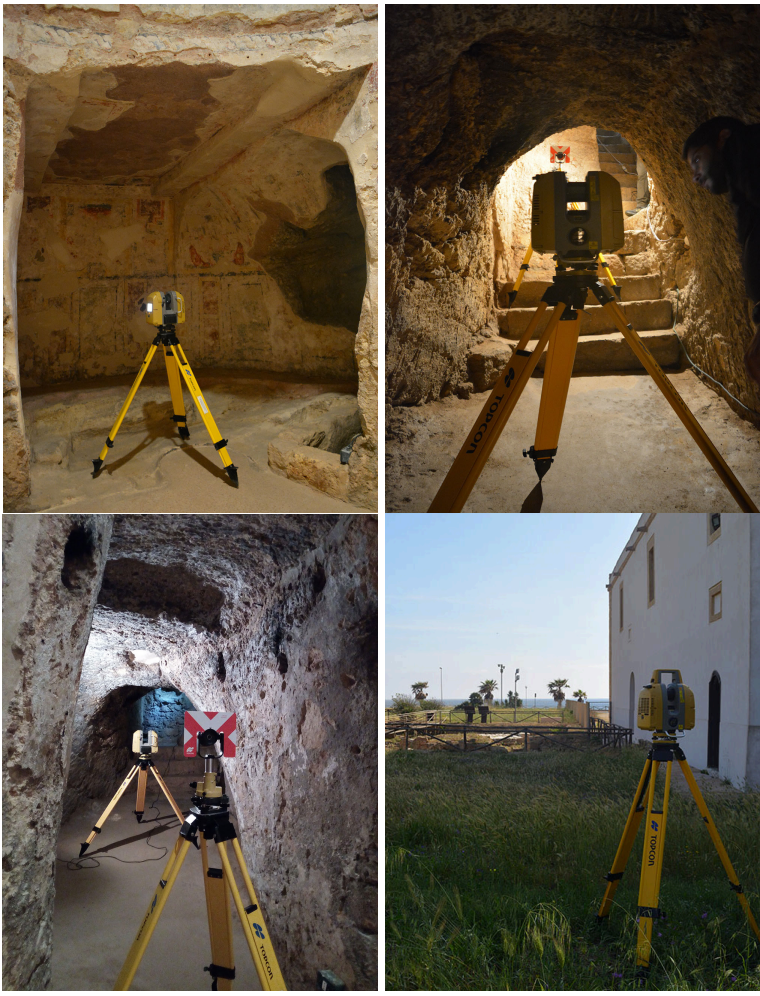

Figure 6. Terrestrial laser scanner survey.

All scans were performed with an average sampling step of 12.5 $\mathrm{mm}$ at $10 \mathrm{~m}$. Because of the topographic approach of the Topcon GLS200M, no targets were positioned and measured. Before every scan acquisition, the instrument has measured the back- and foresight scan positions using a prism positioning on a tripod. This prism scanning data were used to align 3D scanning acquisitions by post-processing.

\subsection{Close-range photogrammetry acquisition}

Since no useful texture is derived from the laser scanner acquisitions, it had to be acquired separately with a highresolution digital camera.

The acquisitions were carried out using a Nikon D5200 digital camera equipped with a $24 \mathrm{~mm}$ lens. The images were acquired all around the inner rooms of the hypogeum in order to 
document wall paintings and mosaic decorations onsite. 116 images were acquired at an average distance of about $3 \mathrm{~m}$ with a Ground Sample Distance (GSD) of $0.5 \mathrm{~mm}$.

Due to the insufficient environment lighting, the images were acquired using a spotlight.

\subsection{UAV acquisition}

The 3D documentation was finally completed by a UAV survey of the exterior of Saint John Church.

The aerial data acquisition was performed with an Aibot X6 V2 hexacopter produced by Aibotix $\mathrm{GmbH}$ equipped with a mirrorless digital camera Olympus PEN E-PL5 with a lens of $17 \mathrm{~mm}$. Two flights were planned with flight mission package AiProFlight by Aibotix GmbH in a "Circular POI (Point of Interest)" mode. This mode allows generating a circular flight plan having the camera pointing to a central point. The first flight was planned from a POI-camera distance of $25 \mathrm{~m}$, the second flight from a POI-camera distance of $35 \mathrm{~m}$ (Figure 7).

Both flights were carried out from a high over the ground of 25 $\mathrm{m}$ and a camera tilt angle of $40^{\circ}$; an autonomous mode of images acquisition was set for one shot per second.

The circular flights have allowed acquiring images oblique to the façades and to the roof of the monument. The resulting average GSD was about $5.5 \mathrm{~mm}$ for the flight from $25 \mathrm{~m}$ and about $8 \mathrm{~mm}$ for the flight from $35 \mathrm{~m}$.

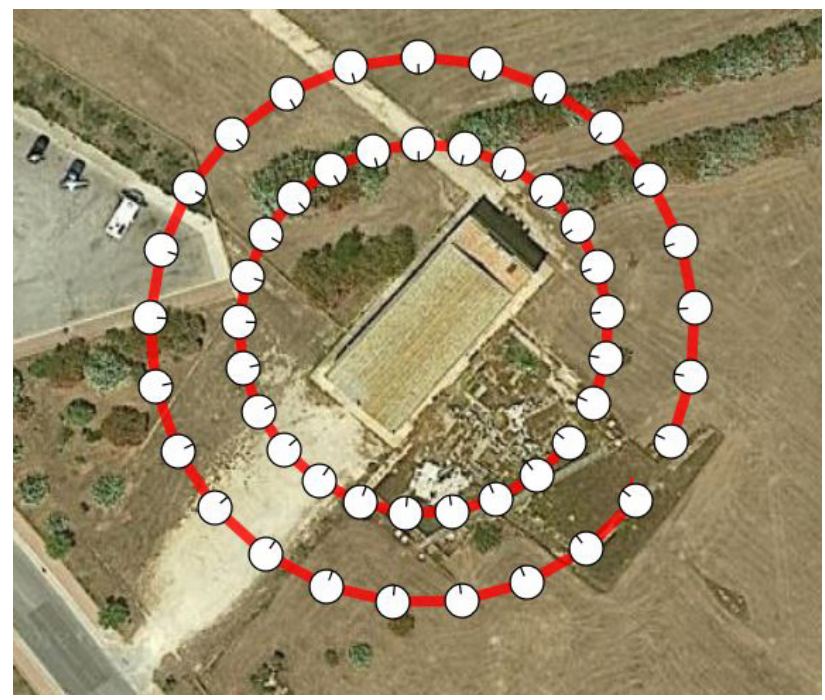

Figure 7. UAV flight plans.

\section{DATA PROCESSING}

All acquired datasets were first processed separately. Then, they were compared and merged, in order to achieve a complete and accurate 3D model of the whole archaeological complex.

The 16 point clouds collected with the terrestrial laser scanner GLS-2000M were processed with Magnet Collage package by Topcon Positioning. The registration of the point clouds was achieved through the traverse method. The traverse started from the scan point $S T 1$, inside the "Sybil hypogeum", which has been set as the origin of the reference system (Figure 8). The second scan point (ST2) was used to orient the traverse; the coordinates of this point have been set equal to zero for $\mathrm{X}$ and $\mathrm{Z}$ and to the distance between $S T 1$ and ST2 for Y. The traverse method allows to set the point ("Occupation point" or "OCC point" ) from which to perform the scan and from which to measure the previous scan point ("Backsight point" or "BS point"). The "Backsight point" has always been measured using a prism placed on a tripod. To ensure the best accuracy on scan registration the "forced centering" approach was adopted between the prism and the laser scanner (and vice versa). In consideration of the environmental and logistical conditions, it was not possible to carry out closed traverses both for the traverse inside the crypt and for the traverse outside the church (Figures 8 and 9).

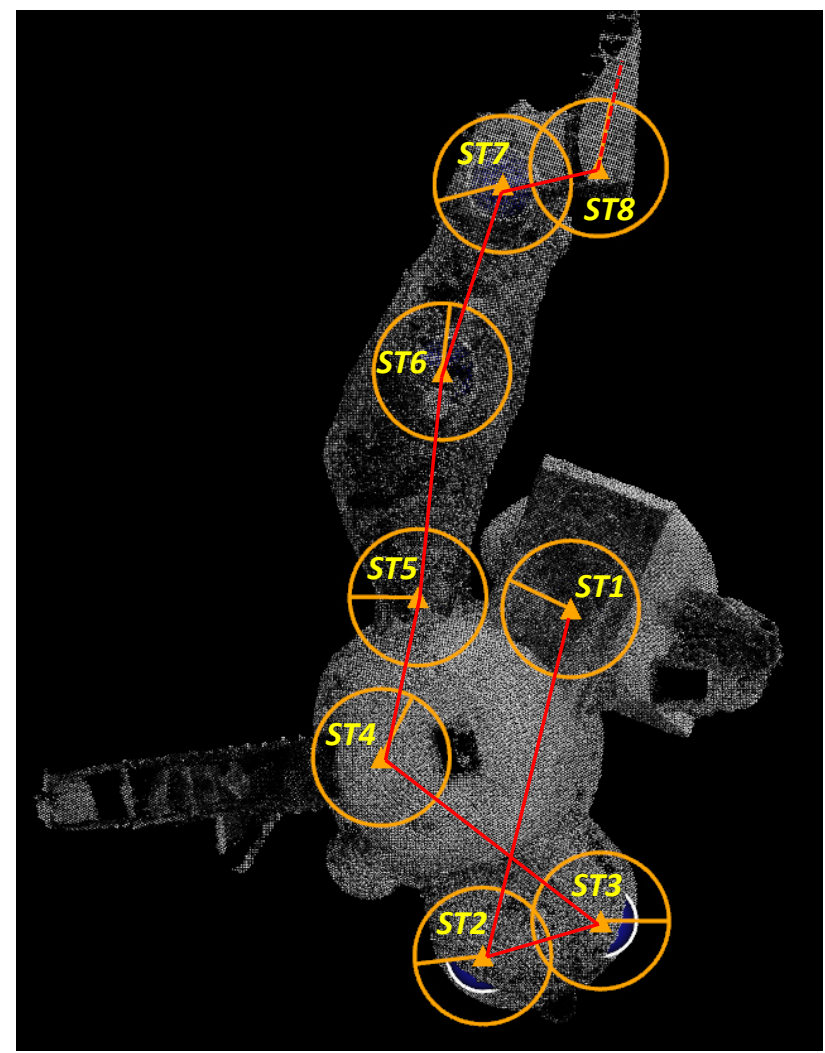

Figure 8. The scheme of scan points inside the "Sybil hypogeum".

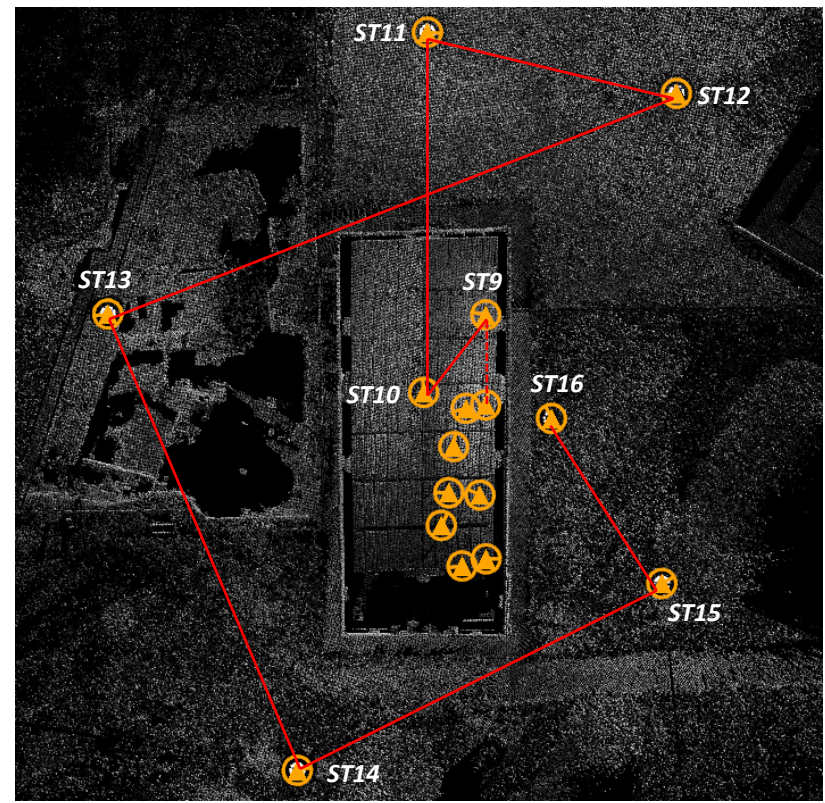

Figure 9. The scheme of scan points inside and outside the Saint John Church. 
The check on the scan registration was then done on the residuals of the coordinates of the scan points calculated by the software Magnet Collage. The Root Mean Square (RMS) and the maximum deviation of all scan points are listed in Table 10.

\begin{tabular}{|c|c|c|c|}
\hline OCC/BS registration & $\boldsymbol{X}(\mathbf{c m})$ & $\boldsymbol{Y}(\mathbf{c m})$ & $\boldsymbol{Z}(\mathbf{c m})$ \\
\hline RMS & \pm 0.1 & \pm 0.1 & \pm 0.8 \\
\hline MAX & 0.1 & 0.1 & 1.4 \\
\hline
\end{tabular}

Table 10. Scans registration RMS and maximum deviation.

In order to improve the registration between the underground and the above scans, two blocks were created, one with all underground scans and another with the inside and outside church scans. A cloud-to-cloud registration was carried out between these two blocks obtaining an RMS of about $\pm 0.2 \mathrm{~cm}$. After this registration, the scans were merged all together; a final point cloud, without the external part of the church roof, of about 60 million points was achieved (Figure 11).

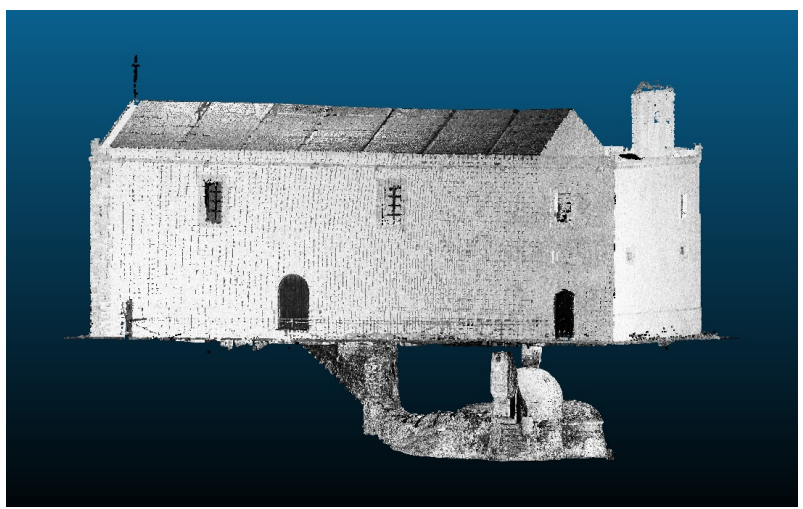

Figure 11. Final point cloud of the terrestrial laser scanner survey.

In order to easily manage this $3 \mathrm{D}$ data, the final cloud was edited by removing all areas not necessary for the $3 \mathrm{D}$ model and was divided into four different regions: the hypogeum rooms, the staircase and the entrance tunnel, the interior of the church and the exterior of the church. The number of points of every single region are listed in Table 12 .

\begin{tabular}{|c|c|}
\hline Scan Region & Number of points \\
\hline Hypogeum & $23,041,386$ \\
\hline Staircase and tunnel & $21,247,289$ \\
\hline Interior of the church & $7,813,237$ \\
\hline Exterior of the church & $13,152,450$ \\
\hline
\end{tabular}

Table 12. Number of points for each scan.

The close-range photogrammetry acquisition of the hypogeum rooms was processed with PhotoScan package by Agisoft LLC using a standard workflow (Automatic image orientation by Structure from Motion, bundle block adjustment to calculate the camera calibration parameters and the exterior orientation parameters, dense image matching to generate $3 \mathrm{D}$ point cloud, 3D reconstructing by polygonal mesh, texture mapping). Some points measured in the terrestrial laser scanner point cloud were used as markers in Photoscan to fix the scale and the reference system of the photogrammetric model. A point cloud of the hypogeum rooms of about 28 million points was produced (Figure 13).

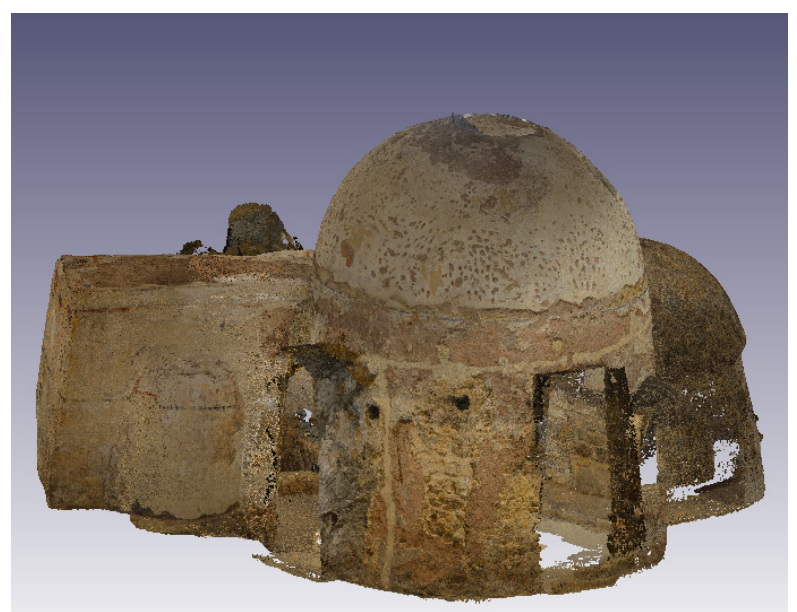

Figure 13. Photogrammetric point cloud of the "Sybil hypogeum".

The aerial acquisition of the exterior of the Saint John Church was processed with Pix4D Mapper package by Pix4D S.A.. A total of 465 images (159 images for the flight from $25 \mathrm{~m}$ and 306 for the flight from $35 \mathrm{~m}$ ) were processed. Also, in this case, a standard Pix4D workflow (Initial processing for keypoints extraction and matching, camera model optimization, point cloud and mesh production) was executed. No ground control points were measured for the UAV acquisition; only the geolocation information, from the camera of the UAV, were used to set the scale and the reference system of the photogrammetric model. A point cloud of about 8 million points was obtained from dense image reconstruction (Figure 14). The point cloud was very noisy so it was necessary to edit it with manual and automatic procedures of noise reduction.

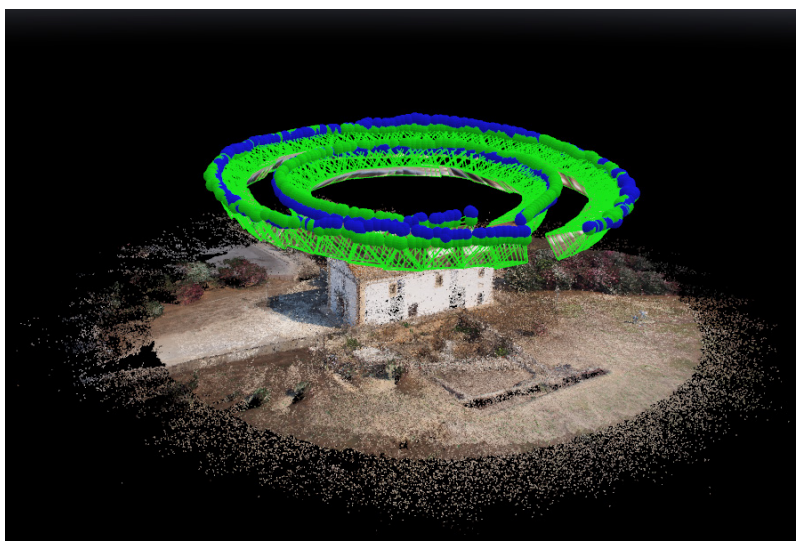

Figure 14. Dense point cloud for external part of the Saint John Church from UAV acquisition.

A complete 3D model of the whole archaeological complex (the underground environment and the overlying church) was achieved carrying out an accurate registration between the terrestrial laser scanner point cloud and the photogrammetric point clouds. A cloud-to-cloud alignment with CloudCompare package was necessary to improve or solve this registration phase. The well-known Iterative Closest Point (ICP) algorithm was used in the modified form of CloudCompare which allows adjusting the scale differences between the two datasets. The 
laser scanner/close-range photogrammetry alignment got an RMS of $\pm 0.8 \mathrm{~cm}$; the laser scanner/UAV photogrammetry alignment instead of an RMS of $\pm 1.3 \mathrm{~cm}$.

To evaluate, from a qualitative point of view, any alignment problems between the various datasets, some checks were carried out along vertical and horizontal sections and by means of cloud-to-cloud distance $(\mathrm{C} 2 \mathrm{C})$ procedure in CloudCompare. The figures 15 and 16 show the distribution of the absolute distances for the "Sybil hypogeum" and the exterior of the Saint John Church respectively.

Finally, after the alignment checks, all the datasets (laser scanner, close-range photogrammetry and UAV photogrammetry) were merged to achieve a complete $3 \mathrm{D}$ documentation of the whole articulated complex, from the underground rooms to the outside of the church (Figure 17).

\section{CONCLUSIONS}

The integration of geomatics techniques combines the advantages of each methodology and allows to record cultural context in all its parts, in order to completely represent the original object.

In our work, the integration of survey methodologies has allowed achieving accurate documentation of archaeological decorated underground environments from a geometric and chromatic point of view.

Terrestrial laser scanner survey produced very accurate geometrical data, but it did not produce high-resolution textures. Moreover, terrestrial laser scanner did not allow documentation of specific portions of the building, such as the roof; so, it was necessary to combine different geomatics techniques.

In addition to the requirement for a complete documentation, some logistical issues, related to the site, have to be overcome, such as the irregular shapes and the narrow spaces of the archaeological complex, the insufficient environment lighting in the underground rooms, the orientation and registration of underground surveys to the surface ones.

All these problems have been overcome with a detailed survey planning and with the employment of different survey approaches.

The final result was a complete and accurate 3D model of the whole archaeological site, from the "Sybil hypogeum" to the outside of the Saint John Church. The model can be used for archaeological analysis and virtualization purposes. Moreover, it becomes also an important source for the underground decoration record, useful for diagnostic and conservation works.

\section{ACKNOWLEDGEMENTS}

The surveys in the Archaeological Park of Lilibeo are related to the project "The Archaeological Map of Lilybaeum" conducted in a partnership with the Department of Cultural Studies of the University of Hamburg and the Department Cultures and Societies and the Department of Engineering of the University of Palermo.

The authors are grateful to Topcon Positioning Italy Srl. and, in particular to Mario Fucile, for providing the laser scanner GLS2000-M and for support in the phase of acquisition and processing.

The authors would like also to thank Maria Grazia Griffo and Anna Maria Parrinello of the Lilibeo - Baglio Anselmi Regional Archaeological Museum, that allowed to carry out the execution of the surveys.

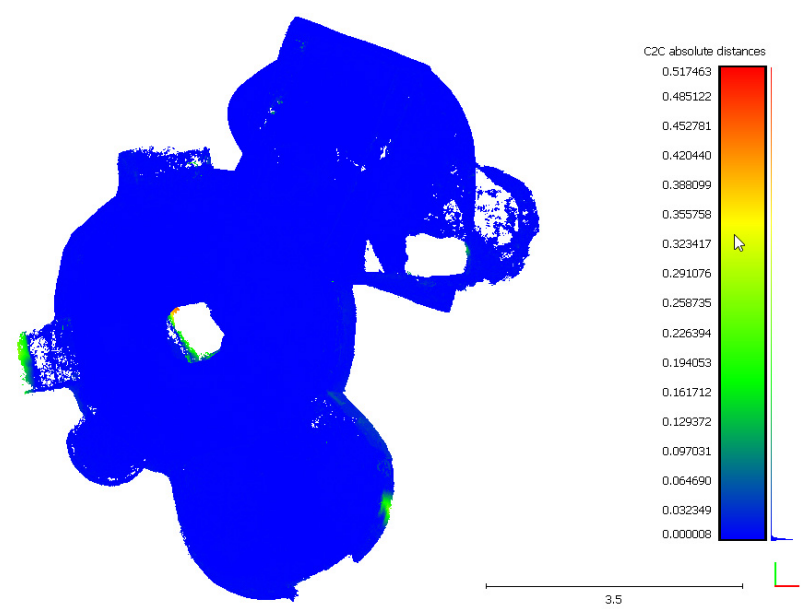

Figure 15. Absolute distances (in meters) between terrestrial laser scanner and close-range photogrammetric point cloud for the "Sybil hypogeum".

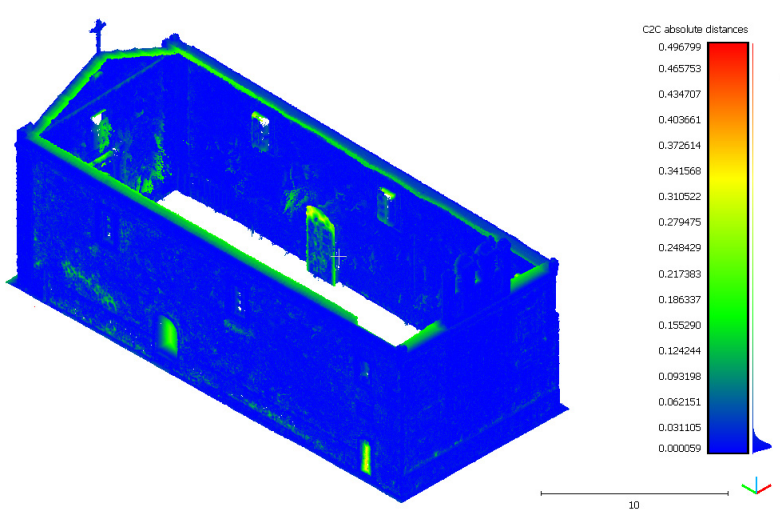

Figure 16. Absolute distances (in meters) between terrestrial laser scanner and UAV photogrammetric point clouds for the external part of the Saint John Church.

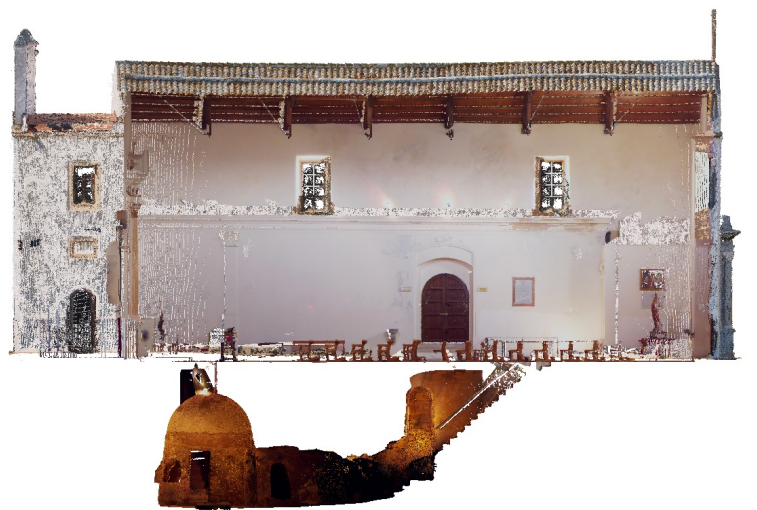

Figure 17. Section of the final 3D model.

\section{REFERENCES}

Basantes, J., Godoy, L., Carvajal, T., Castro, R., Toulkeridis, T., Fuertes, W., Aguilar, W., Tierra, A., Padilla, O., Mato, F., Ordoez, E. and Addisson, A., 2017. Capture and processing of geospatial data with laser scanner system for 3D modeling and virtual reality of Amazonian Caves. In: IEEE Second Ecuador Technical Chapters Meeting, pp. 1-5. 
Beraldin, J. A., Picard, M., El-Hakim, S. F., Godin, G., Valzano, V., Bandiera, A. and Latouche, C., 2002. Virtualizing a Byzantine Crypt by Combining High-resolution Textures with Laser Scanner 3D Data. In: Proceedings of VSMM, Gyeongju, Korea. 25-27 September 2002, pp. 3-14.

Chías, P., Abad, T. Echeverría, E. De Miguel M. and Llorente, P., 2017. Underground surveying: $16^{\text {th }}$ century cellar vaults in the Gallería de Convalecienties, monastery of san Lorenzo del Ecorial. In: International Archives of the Photogrammetry, Remote Sensing and Spatial Information Sciences, Vol. XLII2/W3, pp. 179-186.

https://doi.org/10.5194/isprs-archives-XLII-2-W3-283-2017.

Cusenza, M.C. and Vecchio, P., 2008. La Chiesa di S. Giovanni al Boeo a marsala: gli interventi di restauro e lo scavo archeologico. Sicilia Archeologica XXXIX, 104 (2006), pp. 121-132.

Davis, A., Belton, D., Helmholz, P., Bourke, P. and McDonald, J., 2017. Pilbara rock art: laser scanning, photogrammetry and 3D photographic reconstruction as heritage management tools. Heritage Science, 5:25, pp. 1-16.

Dostal, C., Yamafune, K., 2018. Photogrammetric texture mapping: A method for increasing the Fidelity of 3D models of cultural heritage materials. Journal of Archaeological Science: Reports 18, pp. 430-436.

https://doi.org/10.1016/j.jasrep.2018.01.024

Fais, S., Casula, G., Cuccuru, F., Ligas, P. and Bianchi, M. G., 2018. An innovative methodology for the non-destructive diagnosis of architectural elements of ancient historical buildings. Scientific Reports, 8:4334, pp. 1-11.

Gallay, M., Kaňuk, J., Hochmuth, Z., Meneely, J. D., Hofierka, J. and Sedlák, V., 2015. Large-scale and high-resolution 3-D cave mapping by terrestrial laser scanning: a case study of the Domica Cave, Slovakia. International Journal of Speleology, 44 (3), pp. 277-291.

Lima, M. A., 1997. La Grotta della Sibilla. In: M. G. Griffo Alabiso (a cura di), Marsala, Marsala-Palermo, pp. 122-127.

Lindgren, S. and Galeazzi, F., 2013. 3D laser scanning in cave environment: The case of Las cuevas, Belize acquisition of the cave system and excavation area. In A.C. Addison, G. Guidi, L. De Luca \& S Pescarin (eds), 2013 Digital Heritage International Conference. IEEE, pp. 219-222.

Lo Brutto, M., Sciortino, R., and Garraffa, A., 2017. RPAS and TLS techniques for archaeological survey: the case study of the archaeological site of Eraclea Minoa (ITALY). In: International Archives of the Photogrammetry, Remote Sensing and Spatial Information Sciences, Vol. XLII-2/W3, pp. 433-438, https://doi.org/10.5194/isprs-archives-XLII-2-W3-433-2017.

Lo Brutto, M., Ebolese, D., Dardanelli, G. and Fazio, L., 2018. 3D survey and modelling of the main portico of the Cathedral of Monreale. In: 2018 IEEE International Workshop on Metrology for Archaeology and Cultural Heritage (MetroArchaeo 2018) Proceedings, Cassino, Italy, October 2224, 2018, pp.266-270.

Majid, Z., Ariff, M.F.M., Idris, K.M., Yusoff, A.R., Aspuri, A., Abbas, M.A., Zainuddin, K. and Ghani, A.R.A., Ardi, 2017. Three-dimensional mapping of an ancient cave painting using close-range photogrammetry and terrestrial laser scanning technologies. In: International Archives of the Photogrammetry, Remote Sensing and Spatial Information Sciences, Vol. XLII-
2/W3, pp. 453-457, https://doi.org/10.5194/isprs-archives-XLII2-W3-453-2017.

Saulli, T., Wahbeh, W., Nardinocchi, C., 2018. 3D survey and digital models as the first documentation of hypogeum of $\mathrm{S}$. Saba in Rome. Applied Geomatics, Vol. 10, Issue 4, pp $377-$ 384, https://doi.org/10.1007/s12518-018-0244-0.

Remondino, F., Rizzi, A., Jimenez, B., Agugiaro, G., Baratti, G., Amicis, R., 2011. The Etruscans in 3D: From Space to Underground. Geoinformatics FCE CTU, 6, pp. 283-290, https://doi.org/10.14311/gi.6.35.

TOPCON, 2018. https://www.topconpositioning.com/, Access December 2018.

Torres-Martínez, J. A., Sánchez-aparicio, L. J., HernándezLópez, D., González-Aguilera, D., 2017. Combining geometrical and radiometrical features in the evaluation of rock art painting. Digital Applications in Archaeology and Cultural Heritage, 5, pp. 10-20.

https://doi.org/10.1016/j.daach.2017.04.001. 